\title{
Short Communication Association of rib anomalies and childhood cancers
}

\author{
H Zierhut', M Murati ${ }^{2}$, T Holm², E Hoggard ${ }^{2}$ and LG Spector ${ }^{*, 3}$ \\ 'Departments of Pediatrics and Masonic Cancer Center, University of Minnesota, MMC 484, 420 Delaware Street SE, Minneapolis, MN 55455, USA; \\ ${ }^{2}$ Department of Radiology, University of Minnesota Amplatz Children's Hospital, MMC 292, 420 Delaware St SE, Minneapolis, MN 55455, USA; \\ ${ }^{3}$ Departments of Pediatrics and Masonic Cancer Center, University of Minnesota, MMC 7 I5, I- 187 Moos, 420 Delaware Street SE, Minneapolis, MN \\ 55455, USA
}

BACKGROUND: Congenital anomalies have been found more often in children with cancer than in those without. Rib abnormalities (RAs) have been associated with childhood cancer; however, studies have differed in the type of RAs and cancers implicated. METHODS: Rib abnormalities were assessed predominantly by $X$-ray in a hospital-based case-control study.

RESULTS: There was a significant difference in the number of cases vs controls with RAs after controlling for age and sex, specifically for acute myelogenous leukaemia, renal tumours, and hepatoblastoma.

CONCLUSION: The results of this study support previous reports that there is an association of rib anomalies with childhood cancer. British Journal of Cancer (201 I) 1 05, I392- 1395. doi:10.1038/bjc.20 I I.366 www.bjcancer.com

Published online 13 September 2011

(c) 20II Cancer Research UK

Keywords: childhood cancer; rib anomalies; congenital anomalies

Multiple studies have demonstrated an association between morphological abnormalities and paediatric cancer (Evans et al, 1993; Narod et al, 1997; Merks et al, 2008). Associations between congenital anomalies and cancer predisposition syndromes are noted in single gene disorders such as Gorlin syndrome, Fanconi anaemia, and Wilm's tumour 1 mutation-related disorder (WT1) (Pelletier et al, 1991; Cowan et al, 1997; Kimonis et al, 1997; Alter et al, 2003). Even in the absence of single gene disorders, several epidemiological studies have provided data showing an association between childhood cancer and rib anomalies (RAs; Schumacher et al, 1992; Merks et al, 2005; Loder et al, 2007). Normally, an individual has 12 pairs of ribs with a total of 24 ribs. Abnormalities of the ribs can be numerical (e.g., $>24$ or $<24$ ribs) or structural (e.g., cervical ribs, bifid ribs, synostoses, and segmentation defects). All three previous studies examining RAs have reported an association with childhood cancer; however, the studies differed in the specific type of RAs implicated. This study sought to better understand and more robustly describe the association between childhood cancer and morphological defects of the ribs in a US population.

\section{MATERIALS AND METHODS}

\section{Subject selection}

Rib anomalies were assessed in a hospital-based case-control study. Cases consisted of all paediatric haematology and oncology and bone marrow transplantation (BMT) patients treated at the University of Minnesota Medical Center-Fairview in Minneapolis, MN for malignancy during 2003-2009. Cases must have been diagnosed between the ages of $0-19$ years and had been imaged during the study period. Children with a known syndrome (e.g., bone marrow failure syndromes, Down's syndrome, and mucco-

*Correspondence: Dr LG Spector; E-mail: spect012@umn.edu Received 9 May 2011; revised 12 August 2011; accepted 17 August 20 I ; published online 13 September 201 I polysaccaridoses) identified through our database were excluded; we expect that only very minimal number of syndromic cases were missed. Controls were randomly selected paediatric patients who received a chest X-ray at Fairview Ridges Hospital in Burnsville, MN during June and October of 2003-2008. Controls were chosen from this community hospital as they more likely represent the general Twin Cities paediatric population. Indications for chest X-rays in controls included asthma or shortness of breath, bronchitis, chest pain, possible pneumonia, trauma, and others (e.g., foreign body). The study was approved by the University of Minnesota Institutional review board.

\section{Data collection and quality assurance}

Images were reviewed for numerical and structural RAs according to previously described scoring methods (Coury and Delaporte, 1954; Merks et al, 2005). The latter were cervical ribs (left, right, or bilateral not including transverse apophysomegalies), bifid ribs (left, right, or bilateral), rib synostoses/fusion (left, right, and bilateral), vertebral segmentation anomaly, and post-surgical repairs. Chest X-rays were evaluated whenever possible, with additional images evaluated when clarification was needed. When a chest X-ray was unavailable, magnetic resonance imaging or computed tomography (CT) was evaluated. An electronic database was created using FileMaker Pro 10 software (Filemaker Inc., Santa Clara, CA, USA) to assist in abstracting data. The abstraction instrument was first tested by two radiologists independently reviewed a random sample of 100 images to assess the interrater reliability ( $\kappa$ statistic) of the abstraction tool. The initial abstraction tool showed substantial agreement for the availability of images (Kappa $(\kappa)=1.00)$, rib number $(\kappa=0.75)$, and bifid ribs $(\kappa=0.79)$ (Landis and Koch, 1977). Moderate agreement was noted for the evaluability of images $(\kappa=0.57)$ and cervical ribs $(\kappa=0.52)$. Improvements to the abstraction tool included clarification of the definition of which images were considered not evaluable due to the inability to clearly visualise the C7 and L1 vertebra. After the original review of images, two radiologists 
analysed all positive images. Of the 82 images scored positive by the resident, the radiologists found 77 positive images indicating a $94 \%$ agreement. A complete reanalysis of the radiologists' data found no substantial differences compared with the resident (data not shown).

Using the improved abstraction instrument one radiology resident reviewed each radiograph, followed by post hoc evaluation of a random sample of 100 images by two radiologists to determine interrater reliability of availability of images $(\kappa=1.0)$, evaluability of images $(\kappa=0.80)$, and the presence of RA $(\kappa=0.85)$. The high level of agreement between the radiologists and radiology resident provided confidence to allow the resident's evaluations to stand in the analysis. Blinding reviewers to case status was not entirely possible; however, they were not made aware of the study's hypothesis until completion of data collection.

\section{Statistics}

Pearson's $\chi^{2}$-test was used to assess categorical data differences between cases and controls. Dichotomous variables were created for normal or abnormal ribs (any RA including abnormal rib number, cervical ribs, bifid ribs, and rib synostoses), rib number (24 and $<24,>24)$, cervical and bifid ribs. Only one rib synostoses/fusion or segmentation defects were detected and so these were not analysed. All cases as well as individual cancer types with greater than five RAs were analysed. Unconditional logistic regression was used to calculate the ORs and 95\% CI for RAs adjusting for age and sex.

Sensitivity analyses were completed to examine the possibility of bias introduced from the selection of cases and controls; these included analyses with each indication for X-ray in controls dropped in turn, exclusion of all individuals who resided outside the state of Minnesota, restriction by image type, and separate analyses of paediatric BMT and haematology/oncology patients. All statistical analyses were performed using SAS Version 9.2 software (SAS Institute Inc., Cary, NC, USA).

\section{RESULTS}

There were 625 eligible cases (paediatric haematology/oncology, $n=409$, BMT, $n=216$ ) and 1499 eligible controls (Table 1). Controls had a higher percentage of available images (93.2\%), but a lower percentage of evaluable images $(81.2 \%)$ (Table 2). Cases that had cancer types not frequently requiring chest imaging (e.g., brain tumours) were more likely to have no images available but on the whole most cases had multiple chest X-rays or CT images. Controls on the other hand were selected based on having had a single chest X-ray and the indications for imaging were less likely to necessitate a chest X-ray of the entire rib cage or follow-up imaging. Reasons for non-evaluation included inability to visualise cervical vertebra (C7), lumbar vertebra (L1), both C7 and L1 or poor quality. The resulting ratio of evaluable images for cases to controls was $1: 2.5$. The radiologist used various means for identifying RAs with the preference first via X-ray followed by CT scan. The image types available differed in cases and controls $(P<0.0001)$. Controls had a higher percentage of X-rays $(99.6 \% v s$ $88 \%)$ and cases had a higher percentage of available CTs $(12.0 \% v s$ $0.2 \%$ ) (Table 1 ). Study participants varied significantly by age at first chest imaging, ethnicity, and residence but did not differ by gender (Table 2).

Rib number assessed as an integer differed in cases and controls (Fisher's exact $P$-value $=0.008$ ) (Table 3 ). When categorised as less than or greater than 24 ribs, the crude analysis was borderline significant with an OR of 1.57 (95\% CI: 0.98, 2.53) and when adjusted for age and sex attained significance with an OR of 1.66 (95\% CI: 1.00, 2.74) (Table 4). A similar association was seen after excluding BMT cases $(\mathrm{OR}=1.78,95 \% \mathrm{CI}: 1.01,3.12)$.
Table I Description of images available and evaluable

\begin{tabular}{|c|c|c|c|}
\hline Eligible participants & $\begin{array}{c}\text { Cases } \\
(n=625)\end{array}$ & $\begin{array}{c}\text { Controls } \\
(n=1499)\end{array}$ & $P$-value \\
\hline Available images & $478(78.5 \%)$ & $1398(93.2 \%)$ & \\
\hline Evaluable images & $459(96.0 \%)$ & 1135 (81.2\%) & \\
\hline X-ray & 404 (88.0\%) & $1|3|(99.6 \%)$ & $<0.0001$ \\
\hline CT & $55(12.0 \%)$ & $2(0.2 \%)$ & \\
\hline Other & $0(0.0 \%)$ & $2(0.2 \%)$ & \\
\hline Non-evaluation images & $19(4.0 \%)$ & $263(18.8 \%)$ & \\
\hline Both $C 7$ and LI not visible & $0(0 \%)$ & I (0.3\%) & 0.94 \\
\hline C7 not visible & $10(52.6 \%)$ & $133(50.5 \%)$ & \\
\hline LI not visible & $9(47.4 \%)$ & $125(47.5 \%)$ & \\
\hline Poor quality & $0(0 \%)$ & $4(1.5 \%)$ & \\
\hline
\end{tabular}

Abbreviation: $\mathrm{CT}=$ computed tomography.

Table 2 Demographics of paediatric cancer cases and controls

\begin{tabular}{|c|c|c|c|}
\hline & $\begin{array}{c}\text { Cases } \\
(n=459)\end{array}$ & $\begin{array}{c}\text { Controls } \\
(n=1 / 35)\end{array}$ & $P$-value \\
\hline Age at first chest image (years, s.d.) & $9.42(5.91)$ & $5.57(5.65)$ & $<0.0001$ \\
\hline Age at diagnosis & $8.19(5.91)$ & - & \\
\hline \multicolumn{4}{|l|}{ Gender $^{\mathrm{a}}$} \\
\hline Female & | $82(40.3 \%)$ & $494(43.6 \%)$ & 0.23 \\
\hline Male & $270(59.7 \%)$ & $639(56.4 \%)$ & \\
\hline \multicolumn{4}{|l|}{ Ethnicity $^{\mathrm{a}}$} \\
\hline African-American & 7 (3.5\%) & $111(12.8 \%)$ & $<0.001$ \\
\hline Asian & $9(4.5 \%)$ & $30(3.5 \%)$ & \\
\hline Caucasian & $173(84.6 \%)$ & $627(72.7 \%)$ & \\
\hline Hispanic/Latino & $7(3.5 \%)$ & $50(5.8 \%)$ & \\
\hline Other & $8(4.2 \%)$ & $45(5.2 \%)$ & \\
\hline \multicolumn{4}{|l|}{ Residence } \\
\hline Local (MN resident) & $302(67.4 \%)$ & । 108 (97.9\%) & $<0.0001$ \\
\hline Non-local & $146(32.6 \%)$ & $24(2.1 \%)$ & \\
\hline \multicolumn{4}{|l|}{ Indications for chest $X$-ray in controls ${ }^{a}$} \\
\hline Asthma or shortness of breath & - & $187(16.5 \%)$ & \\
\hline Bronchitis & - & $256(22.5 \%)$ & \\
\hline Chest pain & - & $105(9.3 \%)$ & \\
\hline Possible pneumonia & - & $416(36.7 \%)$ & \\
\hline Trauma & - & $46(4.0 \%)$ & \\
\hline Other & - & $122(10.8 \%)$ & \\
\hline
\end{tabular}

${ }^{a}$ Sex was missing for 2 controls and 7 cases, ethnicity is missing for 272 controls and 254 cases, and indications for chest $\mathrm{X}$-ray were missing in 2 controls.

Table 3 Rib number in paediatric cancer cases and controls

\begin{tabular}{cccc}
\hline & Cases $(\mathbf{N}=\mathbf{4 5 5})^{\mathbf{a}}$ & ${\text { Controls }(\mathbf{N}=\mathbf{I} \mathbf{~ 3 3 3})^{\mathbf{a}}}$ & P-value \\
\hline 20 & $0(0 \%)$ & $1(0.1 \%)$ & 0.008 \\
22 & $10(2.2 \%)$ & $24(2.1 \%)$ & \\
23 & $8(1.8 \%)$ & $2(0.2 \%)$ & \\
24 & $426(93.6 \%)$ & $1086(95.9 \%)$ & \\
25 & $4(0.9 \%)$ & $12(1.1 \%)$ & \\
26 & $7(1.5 \%)$ & $8(0.7 \%)$ & \\
\hline
\end{tabular}

${ }^{a}$ Any noticeable surgical alterations effecting the rib cage were excluded from the analysis (control $=2$ and cases $=4$ ).

Presence of any RA was also borderline significant in the crude analysis $(\mathrm{OR}=1.55,95 \% \mathrm{CI}: 0.98,2.46)$, but significant after adjustment $(\mathrm{OR}=1.60,95 \% \mathrm{CI}: 1.0,2.65)$ (Table 4). Removing 
Table 4 Description of rib anomalies in paediatric cancer cases and controls

\begin{tabular}{|c|c|c|c|c|c|}
\hline & $\begin{array}{l}\text { Total cases } \\
(N=455)\end{array}$ & $\begin{array}{l}\text { Total controls } \\
(N=1133)\end{array}$ & $\begin{array}{c}\text { Crude OR } \\
(95 \% \mathrm{Cl}), P \text {-value }\end{array}$ & $\begin{array}{l}\text { Adjusted OR } \\
(95 \% \mathrm{Cl}), P \text {-value }\end{array}$ & $\begin{array}{l}\text { Adjusted OR }{ }^{\mathrm{b}} \text { without } \\
\text { BMT }(95 \% \mathrm{Cl}), P \text {-value }\end{array}$ \\
\hline Any rib anomalies & $31(6.8 \%)$ & $5 \mid(4.5 \%)$ & $1.55(0.98,2.46), P=0.06$ & $1.60(1.00,2.65), P=0.05$ & $1.81(1.05,3.10), P=0.03$ \\
\hline Cervical ribs & 6 & 9 & $1.67(0.60,4.72), P=0.13$ & $1.63(0.55,4.80), P=0.38$ & $2.61(0.89,7.68), P=0.08$ \\
\hline
\end{tabular}

Abbreviations: $\mathrm{OR}=$ odds ratio; $95 \% \mathrm{Cl}=95 \%$ confidence interval; BMT = bone marrow transplantation. Any rib anomaly including abnormal rib number, cervical ribs, bifid ribs, and rib synostoses. The total rib anomalies are not the sum of abnormal rib number and rib abnormalities due to some individuals who had both abnormal rib number and

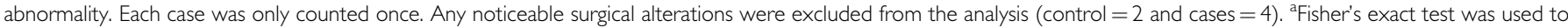
determine the $P$-value for cervical ribs in the crude analysis. ${ }^{b}$ Adjusted for sex and age at first chest imaging.

Table 5 Rib anomalies identified by individual cancer types

\begin{tabular}{|c|c|c|c|c|c|}
\hline & & Normal ribs & Abnormal ribs & Crude OR (95\% Cl) & Adjusted OR $(95 \% \mathrm{Cl})$ \\
\hline Total cancers & 455 & $424(93.2 \%)$ & $31(6.8 \%)$ & $1.55(0.98,2.46)$ & $1.60(1.0,2.65)$ \\
\hline Leukaemias, myeloproliferative diseases, and myelodysplastic & 221 & $206(93.2 \%)$ & $15(6.8 \%)$ & $1.54(0.85,2.80)$ & $1.55(0.84,2.88)$ \\
\hline Lymphoid leukaemias & 105 & $99(94.3 \%)$ & $6(5.7 \%)$ & $1.40(0.58,3.36)$ & $1.27(0.51,3.11)$ \\
\hline Acute myeloid leukaemias & 78 & $70(89.7 \%)$ & $8(10.3 \%)$ & $2.42(1.11,5.31)$ & $2.29(1.02,5.13)$ \\
\hline Chronic myeloproliferative diseases & 20 & $20(100 \%)$ & $0(0.0 \%)$ & - & - \\
\hline Other specified or unspecified leukaemias & 18 & $17(94.4 \%)$ & I $(5.6 \%)$ & $1.36(0.18,10.44)$ & $1.16(0.15,8.98)$ \\
\hline Lymphomas and reticuloendothelial neoplasms & 50 & $49(98.0 \%)$ & I (2.0\%) & $0.47(0.06,3.49)$ & $0.37(0.05,2.89)$ \\
\hline Hodgkin lymphomas & 29 & $29(100 \%)$ & $0(0 \%)$ & - & - \\
\hline Non-Hodgkin lymphomas (except Burkitt's lymphoma) & 12 & | | (91.7\%) & | (8.3\%) & $2.10(0.27,16.63)$ & $1.67(0.21,13.41)$ \\
\hline Other specified or unspecified lymphomas & 9 & $9(100 \%)$ & $0(0 \%)$ & - & - \\
\hline CNS and miscellaneous intracranial and intraspinal neoplasms & 34 & $3 \mid(9 \mid .2)$ & $3(8.8 \%)$ & $2.24(0.66,7.59)$ & $2.00(0.59,6.77)$ \\
\hline Neuroblastoma and other peripheral nervous cell tumours & 31 & $29(93.6 \%)$ & $2(6.4 \%)$ & $1.46(0.34,6.30)$ & $1.48(0.34,6.40)$ \\
\hline Renal tumours & 20 & $17(85.0 \%)$ & $3(15.0 \%)$ & $3.74(1.06,13.19)$ & $3.73(1.05,13.22)$ \\
\hline Malignant bone tumours & 39 & $37(94.9 \%)$ & $2(5.1 \%)$ & $1.15(0.27,4.89)$ & $0.95(0.21,4.31)$ \\
\hline Osteosarcomas & 21 & $19(90.4 \%)$ & $2(9.5 \%)$ & $2.23(0.51,9.85)$ & $1.81(0.38,8.53)$ \\
\hline Ewing tumour and related sarcomas of bone & 15 & $15(100 \%)$ & $0(0 \%)$ & - & - \\
\hline Other specified and unspecified malignant bone tumours & 3 & $3(100 \%)$ & $0(0 \%)$ & - & - \\
\hline Soft tissue and other extraosseous sarcomas & 30 & $29(96.7 \%)$ & | (3.3\%) & $0.73(0.10,5.41)$ & $0.64(0.08,4.91)$ \\
\hline Rhabdomyosarcomas & 15 & $14(93.3 \%)$ & I (6.7\%) & $1.52(0.20,11.75)$ & $1.35(0.17,10.62)$ \\
\hline Other specified or unspecified soft tissue sarcomas & 15 & $15(100 \%)$ & $0(0 \%)$ & - & - \\
\hline Controls & 1133 & $1082(95.5 \%)$ & $51(4.5 \%)$ & - & - \\
\hline
\end{tabular}

Abbreviations: $\mathrm{OR}=$ odds ratio; $95 \% \mathrm{Cl}=95 \%$ confidence interval; $\mathrm{CNS}=$ central nervous system.

BMT cases strengthened the association $(\mathrm{OR}=1.81,95 \% \mathrm{CI}: 1.05$, 3.10). Cervical ribs were the only structural RA with sufficient numbers of events to permit analysis. A description of all RAs is available via online Supplementary Table 1. The inclusion of all cases demonstrated no association between cervical ribs and paediatric cancer in the crude and adjusted models. Removal of BMT cases increased the OR, but it was not significant.

Individual cancer types with substantial numbers of RAs $(n>15)$ are noted in Table 5. Cases with renal tumours and acute myelogenous leukaemia (AML) had a statistically significant increased odds of RAs compared with all controls in both the crude and adjusted models. Hepatoblastoma was not included in our main analysis due to a limited number of cases, but two out of the five cases had a RA $\left(\mathrm{OR}_{\text {crude }}=14.14,95 \%\right.$ CI: $2.34,88.83$, $\left.\mathrm{OR}_{\text {adjusted }}=14.43,95 \% \mathrm{CI}: 2.34,88.83\right)$. All other cancer types did not show a significant association with RAs (Table 5). The same analysis was completed for the association of abnormal rib number as opposed to total RAs and individual cancer type with similar findings (data not shown).

Dropping each control X-ray indication or BMT cases did not markedly alter results (data not shown). Excluding all individuals living outside the state of Minnesota or X-ray only images greatly reduced the number of analysable cases making the associations essentially null. Interestingly, when RAs and rib number were separated into two ethnic categories (Caucasian and nonCaucasian) a statistically significant result was noted for nonCaucasians $(\mathrm{OR}=2.13,95 \% \mathrm{CI}: 1.1,4.08)$ but not in Caucasians alone $(\mathrm{OR}=1.06,95 \% \mathrm{CI}: 0.44,2.53)$.

\section{DISCUSSION}

We detected a moderate but fairly consistent association of RAs and childhood cancer, which remained despite several sensitivity analyses that we performed to compensate for limitations. The findings further appeared to be strongest in AML, renal tumours, and hepatoblastoma. Our results offer partial confirmation of three previous studies on the topic. Loder et al (2007) and Schumacher et al (1992) reported an association of RAs with abnormal rib number whereas Merks et al (2005) failed to confirm this association. Merks et al and Schumacher et al (1992) found an association of cervical ribs and overall childhood cancer, but the studies showed discrepant results between which childhood cancers were associated with cervical ribs. It should be noted that transverse apophysomegalies were not included in our definition of cervical ribs, which may account for the lack of a positive association found in our study. Our results are similar to Loder et al (2007) with a small percentage of identifiable cervical ribs and 
a significant association of abnormal rib number with paediatric cancer. We did not see significant associations with other cancers previously reported with the exception of Wilm's tumour (Schumacher et al, 1992). Our results exhibited an increased number of RAs in CNS neoplasms but the result was not significant. A reduced number of CNS and miscellaneous intracranial and intraspinal neoplasms in our analysis may have prohibited power to detect a significant association.

The US study by Loder et al (2007) is closest to our population and may account for the similarity of results between the studies. Data on RAs may not be generalisable to all ethnic populations. To the extent that we could rely on the data supplied and examine ethnicity (Caucasian and non-Caucasian), we found an association limited to non-Caucasians although this is not a large percentage of our study population. Future studies may help to better understand the role of ethnicity on RAs and the association with childhood cancer.

The hospital-based case-control study design had several limitations. The study population was created from a convenience sample which to some extent limited our analyses. Case and control selection has the potential to introduce bias. Cases in our study were obtained from a tertiary care centre. Cases were likely unaware of RAs and therefore unlikely to be differentially ascertained based on this basis. The underlying cohort that gave rise to the cases in our study would be difficult to define. In an attempt to best replicate the cohort, controls were obtained from a hospital-based clinic to better represent the paediatric population

\section{REFERENCES}

Alter BP, Greene MH, Velazquez I, Rosenberg PS (2003) Cancer in Fanconi anemia. Blood 101: 2072

Coury C, Delaporte J (1954) Congenital abnormalities of the rib: anatomo-radiological forms and practical effects: 288 cases. Sem Hop 30: $2656-2681$

Cowan R, Hoban P, Kelsey A, Birch JM, Gattamaneni R, Evans DG (1997) The gene for the naevoid basal cell carcinoma syndrome acts as a tumour-suppressor gene in medulloblastoma. Br J Cancer 76: 141-145

Evans G, Burnell L, Campbell R, Gattamaneni HR, Birch J (1993) Congenital anomalies and genetic syndromes in 173 cases of medulloblastoma. Med Pediatr Oncol 21: $433-434$

Kimonis VE, Goldstein AM, Pastakia B, Yang ML, Kase R, DiGiovanna JJ, Bale AE, Bale SJ (1997) Clinical manifestations in 105 persons with nevoid basal cell carcinoma syndrome. Am J Med Genet 69: $299-308$

Landis JR, Koch GG (1977) The measurement of observer agreement for categorical data. Biometrics 33: $159-174$ of Minnesota, but we cannot rule out bias due to mismatch between sources of cases and controls. Controls were included in our study for a variety of conditions to dilute any effect of one condition increasing the likelihood of obtaining a chest X-ray due to having a RA.

Our results indicate a modest but fairly robust association between RAs and paediatric cancer generally in line with other findings. Particularly, RAs were associated with increased odds of the individual cancer types AML, renal tumours, and hepatoblastoma. Paediatric cancer aetiology remains an elusive area of research with great need for better understanding. Prospective studies examining the genetics of RAs and childhood cancer may provide insight into the pathways leading to the development of paediatric cancer. The existence of common genetic and/or developmental origins in congenital anomalies and childhood cancer is a rich area for future investigation.

\section{ACKNOWLEDGEMENTS}

This research was supported by the Children's Cancer Research Fund, Minneapolis, MN, USA.

Supplementary Information accompanies the paper on British Journal of Cancer website (http://www.nature.com/bjc)

Loder RT, Huffman G, Toney E, Wurtz LD, Fallon R (2007) Abnormal rib number in childhood malignancy: implications for the scoliosis surgeon. Spine (Phila $\mathrm{Pa}$ 1976) 32: $904-910$

Merks JH, Ozgen HM, Koster J, Zwinderman AH, Caron HN, Hennekam RC (2008) Prevalence and patterns of morphological abnormalities in patients with childhood cancer. JAMA 299: 61-69

Merks JH, Smets AM, Van Rijn RR, Kobes J, Caron HN, Maas M, Hennekam RC (2005) Prevalence of rib anomalies in normal Caucasian children and childhood cancer patients. Eur J Med Genet 48: 113-129

Narod SA, Hawkins MM, Robertson CM, Stiller CA (1997) Congenital anomalies and childhood cancer in Great Britain. Am J Hum Genet 60: $474-485$

Pelletier J, Bruening W, Li FP, Haber DA, Glaser T, Housman DE (1991) WT1 mutations contribute to abnormal genital system development and hereditary Wilms' tumour. Nature 353: $431-434$

Schumacher R, Mai A, Gutjahr P (1992) Association of rib anomalies and malignancy in childhood. Eur J Pediatr 151: $432-434$ 